Research Article

\title{
Reliability Assessment Based on GO Method of Metro Traction System
}

\author{
Qi Gong, ${ }^{1}$ Bingzhi Chen $\mathbb{C D}^{2}$ Yonghua Li $\mathbb{D}^{2},{ }^{2}$ and Pengpeng Zhi $\mathbb{i D}^{1}$ \\ ${ }^{1}$ School of Mechanical Engineering, Dalian Jiaotong University, Dalian 116028, China \\ ${ }^{2}$ School of Locomotive and Rolling Stock Engineering, Dalian Jiaotong University, Dalian 116028, China \\ Correspondence should be addressed to Bingzhi Chen; chenbingzhi06@hotmail.com
}

Received 12 June 2020; Accepted 4 July 2020; Published 21 July 2020

Guest Editor: Shun-Peng Zhu

Copyright $(2020$ Qi Gong et al. This is an open access article distributed under the Creative Commons Attribution License, which permits unrestricted use, distribution, and reproduction in any medium, provided the original work is properly cited.

In order to improve the reliability of the metro traction system (MTS), the whole life cycle of metro vehicles can be operated safely and reliably. A reliability assessment method based on the GO method of the MTS is proposed. In this paper, the reliability assessment is completed without operation service failure of the metro vehicle. The maintainability and shutdown correlation of many electrical components in the MTS are considered. An accurate algorithm with shared signals is used. Then the quantitative and qualitative reliability assessment of the system is achieved with the goal of traction system providing traction for the vehicle. The evaluation identifies the weak links of the system. Comparing the completely independent quantitative calculation result of each component with the accurate quantitative calculation results, it is found that the complex correlation in the repairable system has an important effect on the reliability of the system. A comparative analysis is performed on the calculating results of the GO method and fault tree analysis (FTA) method. The results demonstrate that the reliability analysis of the MTS by the GO method is feasible and reasonable. The principle of the method is simple and the logic is clear. It can not only objectively reflect the working process of the MTS, but also fully characterize the complex correlation with shut down fault in the MTS. The qualitative assessment results of the system show that the cut set probability of the pantograph is the highest, which should be the focus of the MTS.

\section{Introduction}

As a typical representative of urban rapid rail transit, the metro has played an important role in alleviating urban traffic congestion. The traction system is one of the core subsystems of the metro vehicle. Its reliability directly determines whether the vehicle can operate safely. The reliability assessment for the traction system has great significance to the design, production, operation, and maintenance of metro.

Traction system is a complex system. The reliability of the traction system is still a challenge, for safety-critical and mission-critical applications. In recent years, many reliability analysis methods have been proposed to enhance the safety of engineering structures [1-3]. These studies are mainly the reliability analysis on a subsystem or an important module in the traction system such as traction inverter system [4], IGBT module [5, 6], traction motor [7], and pantograph [8]. The purpose of their reliability research is to improve the reliability of the traction system. As a whole, there are few studies on the reliability of the traction system. Liu et al. [9] have put forward a program to evaluate the reliability of $\mathrm{CRH} 3$ high-speed electric multiple units (EMUs) traction drive system based on reliability block diagram model. The CRH3 high-speed EMUs running in different lines are studied, but the complex correlation of traction drive system components and degradation (derating) conditions are not considered. Meng et al. [10] have proposed three states of the system: safety, subsafety, and failure. Based on the three states, they established the Markov state transfer model of CRH3 EMU traction drive system and evaluated reliability. This paper focuses on that the impacts of different components on the system reliability are compared and analyzed. The reliability of the high-speed 
train traction drive system is studied, but the reliability assessment of the MTS is relatively deficient. In this case, the paper proposed an MTS reliability assessment based on the GO method.

Go method is an effective system reliability analysis method, which is especially suitable for system reliability analysis with multiple states and time series [11]. The method has been widely used in the reliability analysis of power system, water supply system, transportation system, manufacturing system, nuclear energy system, and other electromechanical integrated complex systems. It has made some achievements [12-22]. Therefore, this paper selects the GO method to evaluate the reliability of the MTS. There are three degraded (derated) conditions of metro vehicles. In this paper, the corresponding degraded (derated) condition is determined to evaluate the reliability of the metro vehicle without operation service failure $[23,24]$. The system GO model is established with the goal of traction system providing traction for the vehicle. The maintainability and shutdown correlation of many electrical components in the MTS are considered. An accurate algorithm with shared signals is used $[25,26]$. Then the quantitative and qualitative reliability assessment of the system is achieved.

In this work, the GO method for the reliability analysis of the MTS is presented. Section 2 establishes the reliability index of the MTS components. Section 3 introduces the operators commonly used in MTS and reliability evaluation steps of the system. Section 4 takes a MTS as an example to illustrate the effectiveness and practicality of the GO method. The GO model of the system is established, and the quantitative and qualitative reliability assessment is achieved. The FTA is used for comparative analysis. Finally, Section 5 summarizes and concludes.

\section{Determination of MTS Components' Reliability Index}

Traction system is an important part of the metro vehicle, which directly determines whether the vehicle can transport passengers safely, quickly, and efficiently. Therefore, it is necessary to analyze a comprehensive and in-depth reliability analysis of the MTS to find out the fault-prone links of the system. It can provide the basis for the establishment of reasonable system reliability management measures and help to improve the reliability of the system [27]. According to different functional units of the MTS, it mainly includes the following parts: current collection device, high-speed circuit breaker, traction inverter, filter, traction motor, etc. Taking a MTS as an example, its composition structure is shown in Figure 1.

The vehicle consists of two motor cars $M_{P}$ with a pantograph, two motor cars $M$ without pantograph, and two trailers TC. The pantograph obtains power from the catenary to supply power to the traction motors of the own car and the adjacent car. The electric energy is converted into mechanical energy by traction motor, so that the vehicle can obtain traction. The circuit diagram of the MTS is shown in Figure 2.
It can be seen from Figure 2, the vehicle achieves $1500 \mathrm{~V}$ DC from the catenary through the pantograph, then flows through the main isolating switch Q1, and finally supplies it to the vehicle traction system through high-speed circuit breaker. After the high-speed circuit breaker is turned on, the current flows through the filter reactor L1 and the charging circuit. First, the charging contactor is turned on to make the voltage of the supporting capacitor reach the voltage value set by the system requirements. Then, the charging contactor is turned off, and the separating contactor is turned on. Finally, the direct current is inverted into three-phase alternating current through the traction converter and supplied to the traction motor. The working process diagram of the MTS is obtained, as shown in Figure 3.

It can be seen from Figure 3 that the MTS is mainly composed of pantograph, surge arrester, isolating switch, high-speed circuit breaker, wave filter, charging circuit, converter, converter controller, and motor. As these components can continue to be used after maintenance, the MTS is an engineering repairable system. The failure rules of components of the system can be approximately regarded as following the exponential distribution. After continuous work, they have the system average characteristics of stable operation stage [28]. According to the historical maintenance information and experience value of the metro vehicle, its reliability parameters are obtained through probability and statistical analysis [29, 30], as shown in Table 1.

\section{Reliability of the MTS Based on the GO Method}

GO method is a success-oriented method for system reliability analysis, which is suitable for complex system reliability analysis. Taking the traction system providing traction for the metro vehicle as the successful goal, GO operator is used to represent the components of the system. The signal flow of the connection operator is used to represent the transmission path of electric energy received by traction motor. Reliability assessment for the MTS is achieved without operation service failure of the metro vehicle based on the GO method principle of the repairable system. There are three degraded (derated) conditions of metro vehicles. A metro vehicle has 4 motor cars. When the traction system of one motor car fails, the train traction system will output at $75 \%$ of the traction capacity, which will not affect the operation service of the metro train. If two motor cars lose traction, the train traction system will output at $50 \%$ of the traction capacity, and the remaining two motor cars will pull all the cars to the terminal station with normal operation and the car will stop operation for maintenance. If three cars lose traction, the train traction system will output at $25 \%$ of the traction capacity, and the remaining one motor car will pull all the cars to the nearest station to lay down all the passengers and then return to the terminal station to stop operation for maintenance. Both two conditions affect the operation service of the metro vehicle. So at least 3 of 4 


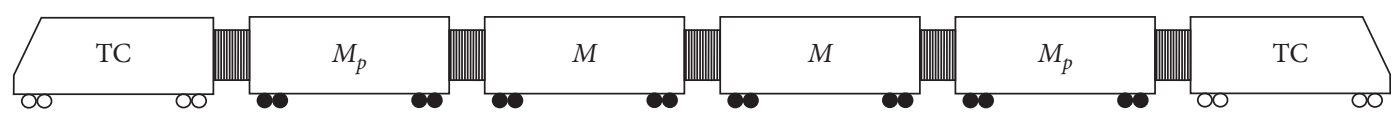

Figure 1: Structure diagram of the MTS.

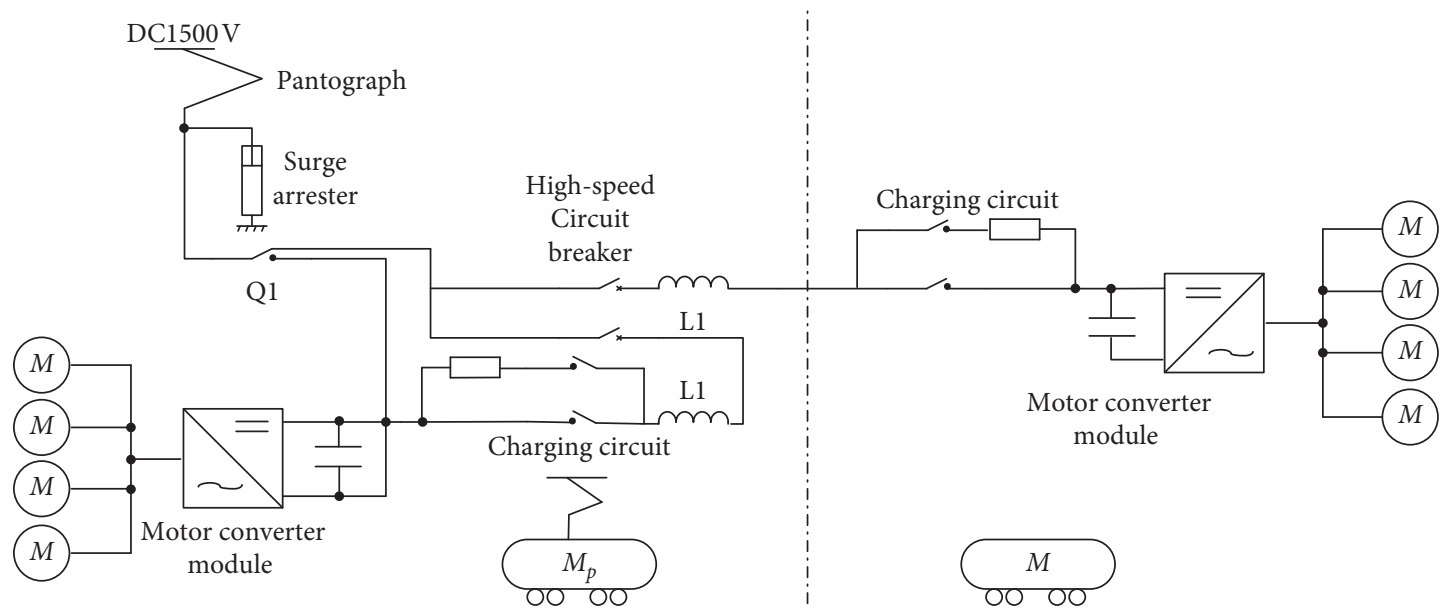

FIgURE 2: Circuit diagram of the MTS.

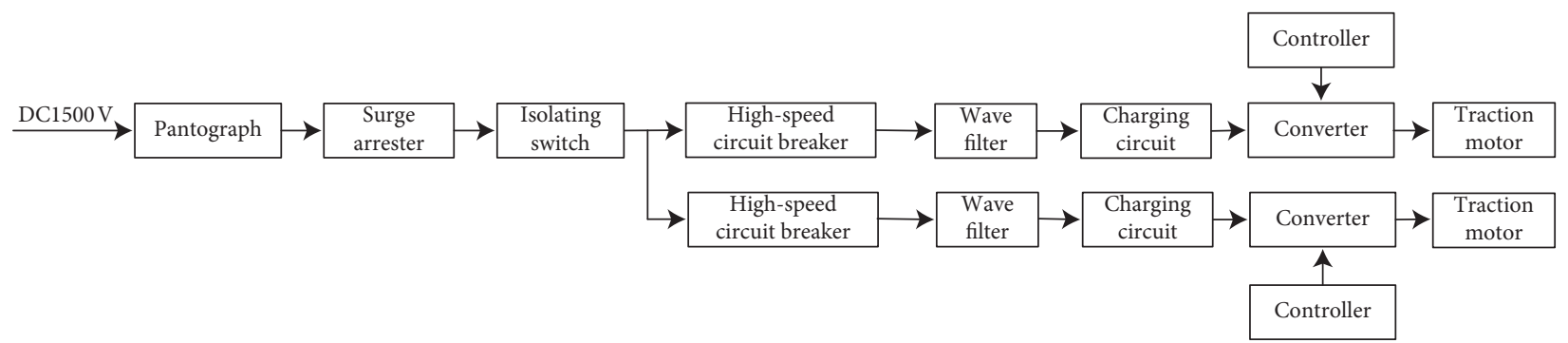

FIgURE 3: Working process diagram of the MTS.

TABLE 1: Reliability parameters of the MTS.

\begin{tabular}{lccc}
\hline Components & Failure rate $\left(\mathrm{h}^{-1}\right)$ & Average maintenance time (h) & Failure probability \\
\hline Pantograph & $1.25 \times 10^{-5}$ & 24 & 0.0003 \\
Surge arrester & $4.2 \times 10^{-6}$ & 6 & 0.0000252 \\
Isolating switch & $4.2 \times 10^{-6}$ & 14 & 0.0000588 \\
High-speed circuit breaker & $4.2 \times 10^{-6}$ & 12 & 0.0000504 \\
Wave filter & $4.146 \times 10^{-6}$ & 12 & 0.00004976 \\
Controller of converter & $2.488 \times 10^{-5}$ & 6 & 0.00014927 \\
Charging resistor & $4.146 \times 10^{-6}$ & 6 & 0.00002488 \\
Charging contactor & $1.244 \times 10^{-5}$ & 6 & 0.00007464 \\
Separating contactor & $1.244 \times 10^{-5}$ & 6 & 0.00007464 \\
IGBT & $2.488 \times 10^{-5}$ & 12 & 0.00029856 \\
Overvoltage chopper & $4.146 \times 10^{-6}$ & 6 & 0.00002488 \\
Voltage sensor & $8.292 \times 10^{-6}$ & 9 & 0.00007463 \\
Current sensor & $8.292 \times 10^{-6}$ & 9 & 0.00007463 \\
Supporting capacitance & $8.292 \times 10^{-6}$ & 9 & 0.00007463 \\
Traction motor & $4.2 \times 10^{-6}$ & 24 & 0.0001008 \\
\hline
\end{tabular}


motor cars work normally, so as not to affect the operation service of metro trains.

3.1. GO Operator Selection. Type 1 operator is a two-state unit. It is the most commonly used operator in MTS. The surge arrester, isolating switch, high-speed circuit breaker, wave filter, charging circuit, and traction motor are twostate components, which we use operator 1. Type 5 operator is a signal generator. It can simulate the input unit. Pantograph is the input of the system, which is represented by type 5 operator. Similarly, controller of the converter signal is also represented by type 5 operator. Type 6 operator is a unit controlled by two control signals, such as a converter, and DC electrical signal and control signal are two input signals. Type 10 operator is the AND gate. It can simulate the logical relationship that all signals in this structure work normally and the parallel unit can work normally. In the MTS, when four traction motors of a vehicle have electric energy, the traction system of this vehicle is successful. Type 11 operator is the $K$-out-of- $M$ gate. It can represent a parallel repairable system composed of $M$ identical repairable units, among which $K$ units work normally and the system works normally. In the MTS, 3out-of- 4 gate is used. Overall, the five types of operators are used in MTS. These operators are shown in Figure 4. $S$ is the input signal, $R$ is the output signal, and subscript is different input signals.

3.2. Reliability Evaluation Steps of the MTS. The units may have shutdown correlation in a repairable system. As a repairable system, if the MTS is shut down due to some failure components, the fault-free components will stop working with the system shutdown, and no fault will occur again. If the system is repaired, these components will return to work. The components are not independent and have shutdown correlation. The failure laws of these components can be regarded as obeying the exponential distribution. In other words, the failure rate and maintenance rate are a constant. The most worthy of attention for MTS is the average characteristic of system. In this paper, the MTS is used as a repairable system for the quantitative calculation of steady-state reliability. The detailed analysis and calculation process is as follows:

(1) Perform system analysis. According to the structure, working principle and functional composition of the system, the function, boundary, and success rule of the system are determined, and the working process diagram of the system is given. The system reliability index is defined according to the historical fault accumulation data.

(2) Develop system GO model. According to the working process diagram of the system, operators are used to represent repairable components, and signal flow is used to connect operators. A system GO model is established composed of operators and signal flow.
(3) Determine the reliability data of all operators in the system. There are some simplified equivalent elements of series structure with shutdown correlation. It is necessary to calculate the parameters of each simplified equivalent element according to equations (1) $-(4)$.

Assuming that the operator corresponds to $M$ shutdown-related series components and the shutdown failure number $I=1$, the equivalent failure rate of the series structure is the sum of the failure rates of all components. Due to shutdown, there is only one component failure in the failure mode of the series structure. There cannot be two or more components fail at the same time. Therefore, the parameters of the simplified equivalent unit are expressed as follows:

$$
\begin{gathered}
\lambda_{R}=\sum_{i=1}^{M} \lambda_{i}, \\
\lambda_{R} \tau_{R}=\sum_{i=1}^{M} \lambda_{i} \tau_{i}, \\
P_{R}(1)=\frac{1}{1+\lambda_{R} \tau_{R}}, \\
P_{R}(2)=\frac{\lambda_{R} \tau_{R}}{1+\lambda_{R} \tau_{R}},
\end{gathered}
$$

where $\lambda_{R}$ is the failure rate of the simplified equivalent unit, $\tau_{R}$ is the average maintenance time of the simplified equivalent unit, $P_{R}$ is the state probability of the simplified equivalent unit, $\lambda_{i}$ is the failure rate of the component, and $\tau_{i}$ is the average maintenance time of the component.

(4) Perform GO operation. According to the GO method for the repairable system, the quantitative calculation of the system is carried out, and the steady-state reliability characteristic quantity of the system is obtained.

The series structure with shutdown correlation should be calculated separately. After obtaining the equivalent reliability parameters of the structure, the equivalent element is used to replace the structure. Then the GO method is used to calculate directly. If the input signal has a shared signal, the shared signal shall be separated first in the process of direct calculation. Then the shared signal shall be combined after the calculation of logic operators. According to equations (1)-(4), the parameters of equivalent units with the shutdown-related series structure in the system are calculated. And the GO method is used to calculate directly according to equations (5)-(32).

The single signal generator operator has no input and only one output signal. It is the input signal of the system. Therefore, the data of the operator are that of the output signal. The output signal data can be written as follows: 


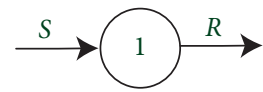

Two-state unit

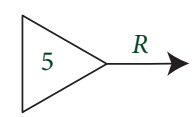

Input unit

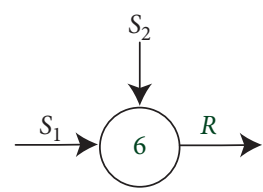

Unit controlled by two control signals

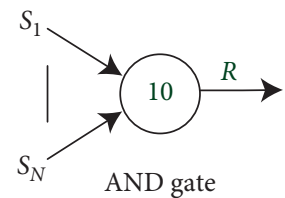

AND gate

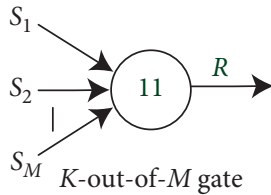

Figure 4: The operators of the MTS.

$$
\begin{gathered}
P_{R}(1)=P_{C}(1), \\
P_{R}(2)=P_{C}(2), \\
\lambda_{R}=\lambda_{C}, \\
\mu_{R}=\mu_{C},
\end{gathered}
$$

where $\lambda_{C}$ is the failure rate of the operator, $\mu_{C}$ is the maintenance rate of the operator, $P_{C}$ is the state probability of the operator, $\lambda_{R}$ is the failure rate of the output signal, $\mu_{R}$ is the maintenance rate of the output signal, and $P_{R}$ is the state probability of the output signal.

The input signals of the operators in the two-state units and the operators are shutdown-related. The number of shutdown failures $I=1$, if one of the input signals and operators stops working, the other will stop without failure. So there is no failure of the input signals and operators at the same time. The output signal data can be expressed as follows:

$$
\begin{aligned}
G_{1} & =P_{S}(1) \cdot P_{C}(1), \\
G_{2} & =P_{S}(1) \cdot P_{C}(2)+P_{S}(2) \cdot P_{C}(1), \\
P_{R}(1) & =\frac{G_{1}}{G_{1}+G_{2}}, \\
P_{R}(2) & =\frac{G_{2}}{G_{1}+G_{2}}, \\
\lambda_{R} & =\lambda_{S}+\lambda_{C}, \\
\mu_{R} & =\frac{\lambda_{R}}{\left(\left(\lambda_{S} / \mu_{S}\right)+\left(\lambda_{C} / \mu_{C}\right)\right)},
\end{aligned}
$$

where $\lambda_{S}$ is the failure rate of an input signal, $\mu_{S}$ is the maintenance rate of an input signal, $P_{S}$ is the state probability of an input signal, $\lambda_{C}$ is the failure rate of operator, $\mu_{C}$ is the maintenance rate of operator, $P_{C}$ is the operator's state probability, $G_{1}$ is the success state probability of the output signal, $G_{2}$ is the failure state probability of the output signal, $\lambda_{R}$ is the failure rate of the output signal, $\mu_{R}$ is the maintenance rate of the output signal, and $P_{R}$ is the state probability of the output signal.

The main input signal and the second input signal of the operator controlled by two control signals have a shutdown correlation with the operator. The number of shutdown failures $I=1$, if one of the two input signals and operators stops working, the other two will stop without fault. Therefore, there is no status of two or three simultaneous faults among the two input signals and operators. The success probability $G_{1}$ of the output signal is the probability that two input signals and operators are in the success state. The failure state $G_{2}$ of the output signal is the total probability that one of the two input signals and operator is in the failure state, and the other two are in the success state. The output signal data are expressed as follows:

$$
\begin{aligned}
G_{1}= & P_{S 1}(1) \cdot P_{S 2}(1) \cdot P_{C}(1), \\
G_{2}= & P_{S 1}(2) \cdot P_{S 2}(1) \cdot P_{C}(1)+P_{S 1}(1) \cdot P_{S 2}(2) \cdot P_{C}(1) \\
& +P_{S 1}(1) \cdot P_{S 2}(1) \cdot P_{C}(2),
\end{aligned}
$$

$P_{R}(1)=\frac{G_{1}}{G_{1}+G_{2}}$,

$P_{R}(2)=\frac{G_{2}}{G_{1}+G_{2}}$,

$$
\begin{aligned}
& \lambda_{R}=\lambda_{S 1}+\lambda_{S 2}+\lambda_{C}, \\
& \mu_{R}=\frac{\lambda_{R}}{\left(\left(\lambda_{S 1} / \mu_{S 1}\right)+\left(\lambda_{S 2} / \mu_{S 2}\right)+\left(\lambda_{C} / \mu_{C}\right)\right)},
\end{aligned}
$$

where $\lambda_{S 1}$ is the failure rate of the main input signal, $\mu_{S 1}$ is the maintenance rate of the main input signal, $P_{S 1}$ is the state probability of the main input signal, $\lambda_{S 2}$ is the failure rate of the second input signal, $\mu_{S 2}$ is the maintenance rate of the second input signal, $P_{S 2}$ is the state probability of the second input signal, $\lambda_{C}$ is the failure rate of the operator, $\mu_{C}$ is the maintenance rate of the operator, $P_{C}$ is the state probability of the operator, $G_{1}$ is the success state probability of the output signal, $G_{2}$ is the failure state probability of the output signal, $\lambda_{R}$ is the failure rate of the output signal, $\mu_{R}$ is the maintenance rate of the output signal, and $P_{R}$ is the state probability of the output signal.

The $N$ input signals of AND gate operator shutdown fault number $I=1$, if one of the $N$ input signals fails, the output signal will be in the failure state. The rest of the $N-1$ input signals will also stop running and will not fail again. 
Therefore, two or more components cannot fail at the same time. The output signal data can be described as follows:

$$
\begin{gathered}
\lambda_{R}=\sum_{i=1}^{N} \lambda_{S i}, \\
\mu_{R}=\frac{\lambda_{R}}{\sum_{i=1}^{N}\left(\lambda_{S i} / \mu_{S i}\right)}, \\
P_{R}(1)=\frac{1}{1+\lambda_{R} \tau_{R}}, \\
P_{R}(2)=\frac{\lambda_{R} \tau_{R}}{1+\lambda_{R} \tau_{R}},
\end{gathered}
$$

where $\lambda_{S i}$ is the failure rate of the input signal, $\mu_{S i}$ is the maintenance rate of the input signal, $\lambda_{R}$ is the failure rate of the output signal, $\mu_{R}$ is the maintenance rate of the output signal, and $P_{R}$ is the state probability of the output signal.

$K$-out-of- $M$ gate represents that in the parallel repairable system composed of $M$ same repairable units, if $K$ units work normally, the system works normally. The parallel repairable system has shutdown correlation, maintenance correlation, and redundance correlation. The output signal data can be described as follows:

$$
\begin{aligned}
a_{i} & = \begin{cases}(M-i+1) \lambda, & \text { when } J=0 \text { or } M-i+2<K \\
K \lambda, & \text { when } J=0 \text { and } M-i+2 \geq K\end{cases} \\
b_{i} & = \begin{cases}i \mu, & i \leq L, \\
L \mu, & i>L,\end{cases} \\
P_{i} & =P_{0} \prod_{j=1}^{i} \frac{a_{j}}{b_{j}}, \\
\lambda_{R} & =\sum_{i=0}^{I} P_{i}, \\
P_{R}(1) & =\sum_{i=0}^{M-K} \frac{P_{i}}{G}, \\
\mu_{R} & P_{M-K} \cdot \frac{a_{M-K+1}}{\sum_{i=0}^{M-K} P_{i}}, \\
P_{R-K+1} \frac{b_{M-K+1}}{\sum_{i=M-K=1}^{I} P_{i}} & \sum_{i=M-K+1}^{I} \frac{P_{i}}{G}
\end{aligned}
$$

where $M$ is the total number of input signals. $K$ is at least number of successful input signals required for output signal success. $I$ is the number of shutdown failures. It represents that when $I$ input signals fail, the system is in shutdown maintenance state, and the rest of the input signals are no longer in failure state. $L$ is the number of maintenance. When $L=M$, it means there is no maintenance-related situation. $J$ is redundance indication. When $J=0$, it means there is no redundance correlation. $a_{i}$ and $b_{i}$ are transfer rates. $a_{i}$ represents the transition rate from the state with $i-1$ failure units to the state with $i$ failure units. $b_{i}$ represents the transition rate from the state with $i$ failure units to the state with $i-1$ failure units. $P_{R}$ is the state probability of the output signal. $\lambda_{R}$ is the failure rate of the output signal. $\mu_{R}$ is the maintenance rate of the output signal.

Using the reliability parameters of system output signal flow, the reliability characteristic quantity of the MTS in the stable operation state is calculated by equations (33)-(38):

$$
\begin{aligned}
A & =\frac{\mathrm{MTBF}}{\mathrm{MCT}}=\frac{\mu}{\lambda+\mu}, \\
\bar{A} & =1-A=\frac{\mathrm{MTTR}}{\mathrm{MCT}}=\frac{\lambda}{\lambda+\mu}, \\
f & =A \lambda=\bar{A} \mu=\frac{1}{\mathrm{MCT}}, \\
\mathrm{MTBF} & =\frac{1}{\lambda}, \\
\mathrm{MTTR} & =\frac{1}{\mu}, \\
\mathrm{MCT} & =\mathrm{MTBF}+\mathrm{MTTR},
\end{aligned}
$$

where $A$ is the average working probability (steady-state availability), $\bar{A}$ is the average failure probability (steady-state unavailability), $f$ is the average number of failures per unit time, $\lambda$ is the failure rate, $\mu$ is the maintenance rate, MTBF is the mean time between failures, MTTR is the average maintenance time, and MCT is the average life cycle.

Through the above analysis, the accurate reliability parameters of the MTS signal flows are determined. The accurate quantitative calculation results of the system reliability evaluation are obtained. The proposed flow diagram of the analysis process is shown in Figure 5.

\section{Example}

4.1. Establishing the GO Model of the MTS. Considering no operation service failure, GO model of the MTS is established with the goal of traction system providing traction for the vehicle based on Figure 3 and the principle of GO method. As shown in Section 3.1, five types of operators are used in the MTS. In order to simplify the GO model, an operator is used to represent the equivalent element composed of multiple series components, such as charging 


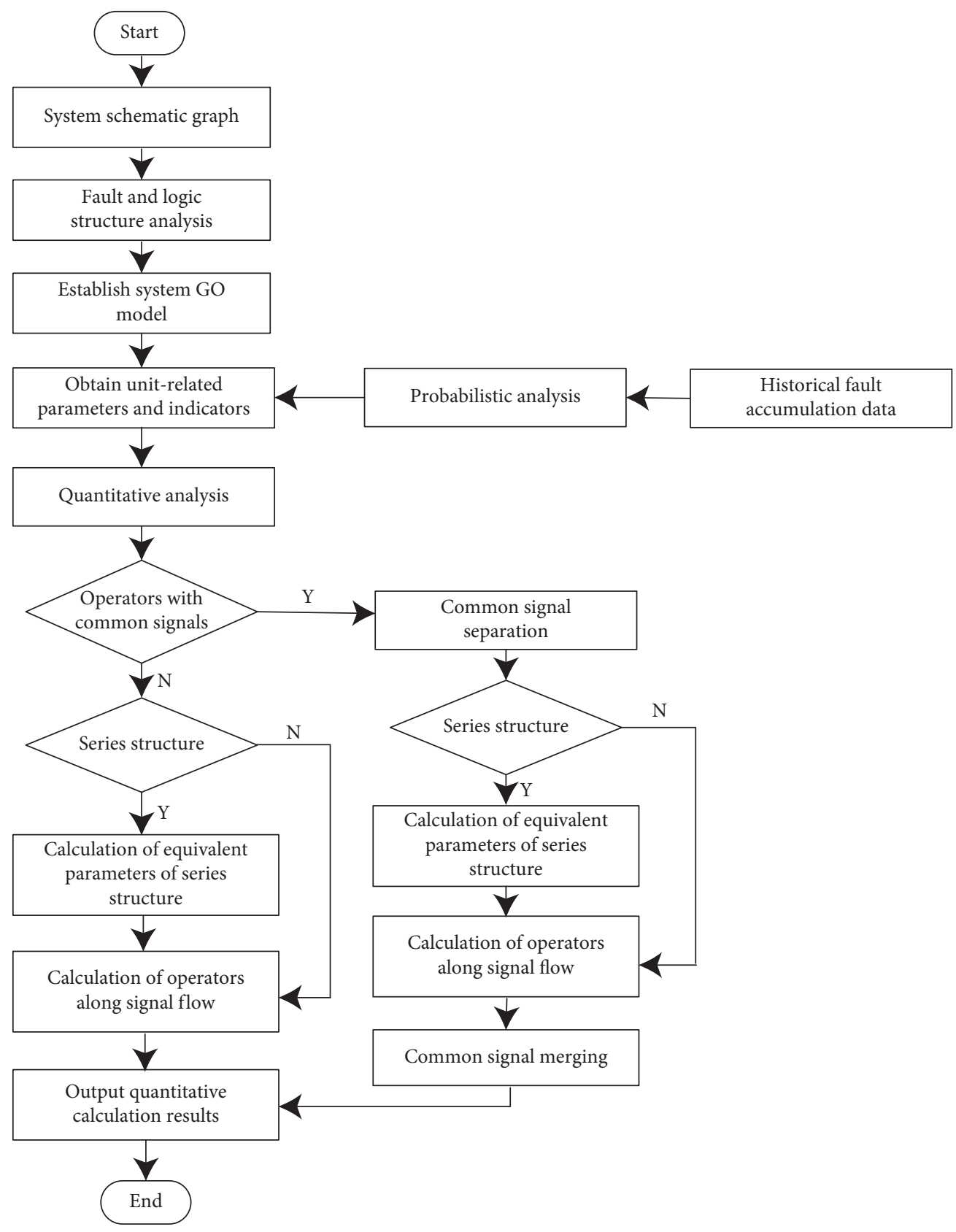

FIgURE 5: The flow diagram of the analysis process of the MTS.

circuit and converter. The GO model of the MTS is shown in Figure 6.

In Figure 6, there are two numbers in the operator symbol. The first is used to represent the type of operator, and the second represents the number of the operator. The numbers on the signal line mean the numbering of signals. If four traction motors of a vehicle have power, the traction system of this vehicle is successful. This logical relationship is represented by type 10 operator. At least three motor cars work normally, and then the metro vehicle works normally and does not affect operation services. This logical relationship is represented by type 11 operator. The system starts from operator 5-1 and 5-2, ends with operator 11-47. From the input operator 5-1 and 5-2, according to the operation rules of the operator, the output signal 47 of the system can be calculated step by step. The reliability characteristic quantity of all signal flows in the system can be obtained. The reliability characteristic quantity of the MTS can be obtained according to the data of the output signal 47 . The operators in Figure 6 are detailed in Table 2.

4.2. Quantitative Calculation of Reliability for the MTS. The basic data used in the calculation are the failure rate of the components $\lambda_{i}$ and the average maintenance time of the components $\tau_{i}$, which can be obtained from Table 1 . 


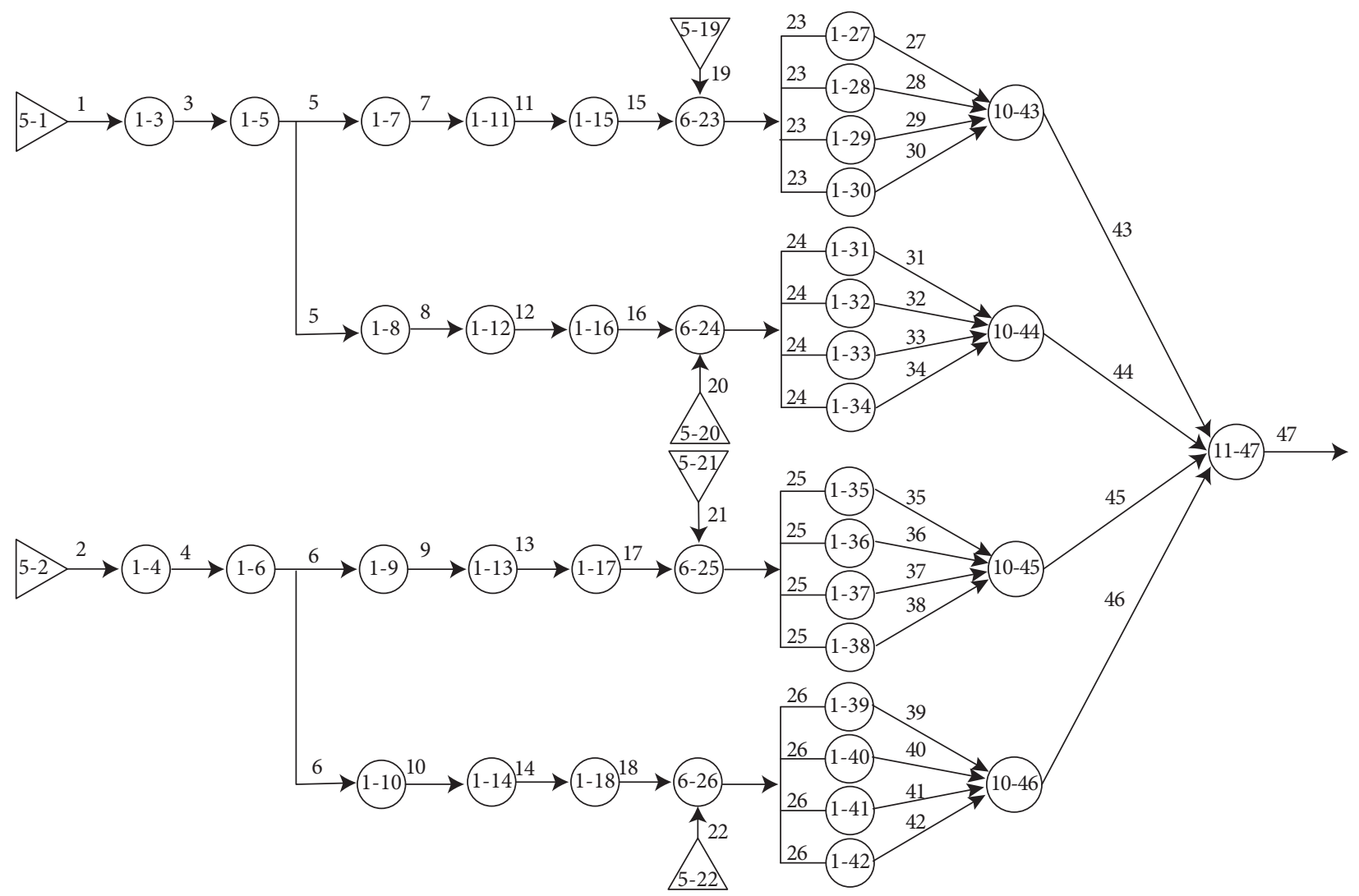

Figure 6: Go model of the MTS.

TABLE 2: Data of operators for the MTS.

\begin{tabular}{lcc}
\hline Number & Type & Representative components \\
\hline 1,2 & 5 & Pantograph \\
3,4 & 1 & Surge arrester \\
5,6 & 1 & Isolating switch \\
$7,8,9,10$ & 1 & High-speed circuit breaker \\
$11,12,13,14$ & Wave filter \\
$15,16,17,18$ & 1 & Charging circuit \\
$19,20,21,22$ & 1 & Controller of converter \\
$23,24,25,26$ & 5 & Converter \\
$27,28,29,30,31,32,33,34,35,36,37,38,39,40,41,42$ & 6 & Traction motor \\
$43,44,45,46$ & 1 & AND gate \\
47 & 10 & 11 \\
\hline
\end{tabular}

4.2.1. Reliability Parameter Calculation of Series Structure. In Figure 6, operator 15 represents the charging circuit. It is equivalent unit composed of charging resistance, charging contactor, and separating contactor. Operators 16,17 , and 18 are the same as operator 15 . Operator 23 represents converter modules. It is equivalent unit composed of IGBT, overvoltage chopper, voltage sensor, current sensor, and supporting capacitor. Operators 24, 25 , and 26 are the same as operator 23. In view of the shutdown correlation of the components, the reliability parameters of operators $15,16,17,18,23,24,25$, and 26 can be obtained from equations (1)-(4) with corresponding $\lambda_{i}$ and $\tau_{i}$, as shown in Table 3 .

Operators 7,11 , and 15 can be assumed to be shutdown-related serial components. The reliability parameters of them can be obtained from equations (1)-(4) and recorded as operators $15^{*}$. Operators 8,12 and $16,9,13$ and $17,10,14$ and 18 are calculated in the same way, and the equivalent reliability parameters are obtained, as shown in Table 4. 
TABLE 3: Reliability parameters of operators 15 (16-18) and 23 (24-26).

\begin{tabular}{lcccc}
\hline Operator number & Failure rate $\left(\mathrm{h}^{-1}\right)$ & Average maintenance time $(\mathrm{h})$ & Working probability & Failure probability \\
\hline $15(16-18)$ & $2.9026 \times 10^{-5}$ & 6 & 0.99982584 & 0.00017416 \\
$23(24-26)$ & $5.3902 \times 10^{-5}$ & 10.1539832 & 0.99945271 & 0.00054729 \\
\hline
\end{tabular}

TABLE 4: Reliability parameters of operators $11^{*}\left(12^{*}-14^{*}\right)$.

\begin{tabular}{lcccc}
\hline Operator number & Failure rate $\left(\mathrm{h}^{-1}\right)$ & Average maintenance time $(\mathrm{h})$ & Working probability & Failure probability \\
\hline $15^{*}\left(16^{*}-18^{*}\right)$ & $3.7372 \times 10^{-5}$ & 7.3399336 & 0.9997257 & 0.0002743 \\
\hline
\end{tabular}

4.2.2. Reliability Parameter Calculation of Single Signal Generator. The steady-state quantitative analysis of the MTS after long-time operation is to calculate the steady-state reliability characteristic quantity of the system output signal flow 47 . The system is divided into two ways, starting from the input operators 1 and 2, respectively, and the operators are calculated quantitatively one by one along the signal flow sequence. Operators 1 and 2 represent pantograph, which provide input signals for the system. Operators 19, 20, 21, and 22 are the control signals of the converter and provide the secondary input signals for the converter. The reliability parameters of operators 1, 2 and 19, 20, 21, 22 can be obtained from equations (5)-(8) with corresponding $\lambda_{i}$ and $\tau_{i}$, as shown in Table 5 .

4.2.3. Reliability Parameter Calculation of Two-State Element. In Figure 6, it is assumed that the two components represented by operators 3 and 5 in one of the two paths are two unit structures related to shutdown. Then quantitative calculation of them should be carried out separately. Their equivalent reliability parameters can be obtained from equations (9)-(14) with the failure rate of an input signal $\lambda_{s}$, the maintenance rate of an input signal $\mu_{s}$, the failure rate of operator $\lambda_{c}$, and the maintenance rate of operator $\mu_{c} . \lambda_{c}$ and $\mu_{c}$ are corresponding $\lambda_{i}$ and $\mu_{i} . \lambda_{s}$ and $\mu_{s}$ are reliability parameter of the previous operator, which is shown in Table 5. Operators 4 and 6 of the other paths are similar, and the equivalent reliability parameters are obtained, as shown in Table 6.

\subsubsection{Calculation of Reliability Parameters of Components} Controlled by Two Control Signals. In Figure 6, operator 23 represents the converter, which is a component controlled by two control signals. The reliability parameters of operator 23 can be obtained from equations (15)-(20) with the failure rate of the main input signal $\lambda_{S 1}$, the maintenance rate of the main input signal $\mu_{S 1}$, the failure rate of the second input signal $\lambda_{S 2}$, the maintenance rate of the second input signal $\mu_{S 2}$, the failure rate of the operator $\lambda_{c}$, and the maintenance rate of the operator $\mu_{c} . \lambda_{S 2}, \mu_{S 2}, \lambda_{c}$, and $\mu_{c}$ are corresponding $\lambda_{i}$ and $\mu_{i} . \lambda_{S 1}$ and $\mu_{S 1}$ are reliability parameter of the previous operator, which is shown in Tables 4 and 5. Operators 24, 25, and 26 are similar, and the reliability parameters are obtained, as shown in Table 7.
4.2.5. Reliability Parameters of AND Gate. In Figure 6, operator 43 is the AND gate operator. According to reliability parameters $\lambda$ and ${ }_{\mu}$ of traction motor in Table 1, operator 43 is calculated by equations (21)-(24) and recorded as operator $43^{*}$. It does not include shared signal 23. Operators 44,45 , and 46 are similar, and the reliability parameters are obtained, as shown in Table 8.

4.2.6. Shared Signal Processing. Since the reliability parameters of AND gate output signal $43^{*}$ do not include shared signal 23 , it is necessary to combine the calculation with them. According to the operation rules of two-state element and the reliability parameters in Tables 7 and 8 , operator $43^{*}$ is calculated and recorded as operator $43^{* *}$. It does not include shared signal 5 . Operators $44^{* *}, 45^{* *}$, and $46^{* *}$ are similar, and the reliability parameters are obtained, as shown in Table 9.

4.2.7. Reliability Parameters of 3-Out-of-4 Gate. In Figure 6, operator 47 is the 3-out-of-4 gate operator, so $M=4, K=3$, and $I=2$. The MTS has no maintenance correlation and redundant structure, so $L=4$ and $J=0$. According to the reliability parameters in Table 9 , operator 47 is calculated by equations (25)-(32) and recorded as operator $47^{*}$. It does not include shared signals 5 and 6 . The reliability parameters are obtained, as shown in Table 10.

4.2.8. Shared Signal Processing. Since the reliability parameters of $47^{*}$ do not include shared signals 5 and 6 , it is necessary to combine the calculation with them. The accurate equivalent reliability parameters of signal 47 are obtained according to the operation rules of two control signal unit and the reliability parameters in Tables 6 and 10 . The reliability parameters of signal flow 47 are obtained, as shown in Table 11.

The reliability analysis results in Table 11 take the shutdown correlation of system components into account. All components are regarded as completely independent for system reliability analysis. The analysis results are compared with Table 11, as shown in Table 12.

It can be seen from Table 12 that the system failure probability is reduced by $0.018 \%$ after considering the shutdown correlation. This is because the failure state of three or four branches at the same time cannot occur after 
TABLE 5: Reliability parameters of operators 1 (2) and 19 (20-22).

\begin{tabular}{lcccc}
\hline Operator number & Failure rate $\left(\mathrm{h}^{-1}\right)$ & Average maintenance time $(\mathrm{h})$ & Working probability & Failure probability \\
\hline $1(2)$ & $1.25 \times 10^{-5}$ & 24 & 0.9997 & 0.0003 \\
$19(20-22)$ & $2.488 \times 10^{-5}$ & 6 & 0.99985073 & 0.00014927 \\
\hline
\end{tabular}

TABLE 6: Reliability parameters of operators 3 (4) and 5 (6).

\begin{tabular}{lcccc}
\hline Equivalent signal flow number & Failure rate $\left(\mathrm{h}^{-1}\right)$ & Average maintenance time $(\mathrm{h})$ & Working probability & Failure probability \\
\hline $3(4)$ & $1.67 \times 10^{-5}$ & 19.4730539 & 0.9996748 & 0.0003252 \\
$5(6)$ & $2.09 \times 10^{-5}$ & 18.3732058 & 0.9996160 & 0.0003840 \\
\hline
\end{tabular}

TABLE 7: Reliability parameters of operators 23 (24-26).

\begin{tabular}{lcccc}
\hline Equivalent signal flow number & Failure rate $\left(\mathrm{h}^{-1}\right)$ & Average maintenance time $(\mathrm{h})$ & Working probability & Failure probability \\
\hline $23(24-26)$ & $1.16154 \times 10^{-4}$ & 8.3587995 & 0.9990297 & 0.0009703 \\
\hline
\end{tabular}

TABLE 8: Reliability parameters of operator $43^{*}\left(44^{*}-46^{*}\right)$.

\begin{tabular}{lcccc}
\hline Equivalent signal flow number & Failure rate $\left(\mathrm{h}^{-1}\right)$ & Average maintenance time $(\mathrm{h})$ & Working probability & Failure probability \\
\hline $43^{*}\left(44^{*}-46^{*}\right)$ & $1.68 \times 10^{-5}$ & 24 & 0.9995970 & 0.0004030 \\
\hline
\end{tabular}

TABLE 9: Reliability parameters of operator $43^{* *}\left(44^{* *}-46^{* *}\right)$.

\begin{tabular}{lcccc}
\hline Equivalent signal flow number & Failure rate $\left(\mathrm{h}^{-1}\right)$ & Average maintenance time $(\mathrm{h})$ & Working probability & Failure probability \\
\hline $43^{* *}\left(44^{* *}-46^{* *}\right)$ & $1.32954 \times 10^{-4}$ & 10.3349622 & 0.9986275 & 0.0013725 \\
\hline
\end{tabular}

considering the shutdown correlation, which slightly operators, which represent the functional components of the

TABLE 10: Reliability parameters of operator $47^{*}$.

\begin{tabular}{lcccc}
\hline Equivalent signal flow number & Failure rate $\left(\mathrm{h}^{-1}\right)$ & Average maintenance time $(\mathrm{h})$ & Working probability & Failure probability \\
\hline $47^{*}$ & $2.180281 \times 10^{-6}$ & 5.1674811 & 0.999988734 & 0.000011266 \\
\hline
\end{tabular}

TABLE 11: Reliability parameters of operator 47.

\begin{tabular}{lcccc}
\hline Equivalent signal flow number & Failure rate $\left(\mathrm{h}^{-1}\right)$ & Average maintenance time $(\mathrm{h})$ & Working probability & Failure probability \\
\hline 47 & $4.3980281 \times 10^{-5}$ & 17.7185443 & 0.99922100 & 0.00077900 \\
\hline
\end{tabular}

reduces the system failure probability. The analysis shows that the influence of complex correlation in the repairable system on the reliability of the system cannot be ignored.

According to equations (25)-(30), the characteristic value of system reliability is calculated with the reliability parameters of operator 42 in Table 11. The quantitative assessment of the MTS is completed. The results are shown in Table 13.

4.3. Qualitative Calculation of Reliability Assessment for the MTS. The qualitative analysis of reliability assessment for the MTS is directly carried out with state probability. Suppose that there are $M$ operators in the GO model besides logical system, respectively. If one of the $M$ operators is in the failure state, its success probability is zero. The state probability of the other operators is unchanged, and the success probability of the system is calculated directly. If the success probability of the system is zero, the failure state of the operator is a firstorder cut set of the system. All the first-order cut sets of the system can be calculated by $M$ operators in turn. Among $M$ operators, two operators are taken out of the first-order cut set, and all the second-order minimum cut sets can be obtained by the same method. Similarly, each order cut set of the system can be obtained. If a lower order cut set is included in the combination of higher order, it is not necessary to calculate the system success probability, so the cut set obtained is the minimum cut set. 
TABLE 12: Reliability analysis results of the MTS when considering different correlations.

\begin{tabular}{lccccccc}
\hline Correlations & $I$ & $L$ & $J$ & Failure rate $\left(\mathrm{h}^{-1}\right)$ & Average maintenance time $(\mathrm{h})$ & Working probability & Failure probability \\
\hline Shutdown & 2 & 4 & 0 & $4.3980281 \times 10^{-5}$ & 17.7185443 & 0.99922100 & 0.00077900 \\
Completely independent & 4 & 4 & 0 & $4.3981900 \times 10^{-5}$ & 17.7288280 & 0.99922086 & 0.00077914 \\
\hline
\end{tabular}

TABLE 13: Reliability characteristic value of the MTS.

\begin{tabular}{|c|c|c|c|c|c|c|c|c|}
\hline $\begin{array}{l}\text { Eigenvalue } \\
\text { type }\end{array}$ & $\begin{array}{c}\text { Average } \\
\text { working } \\
\text { probability }\end{array}$ & $\begin{array}{l}\text { Average } \\
\text { downtime }\end{array}$ & $\begin{array}{c}\text { Average failure } \\
\text { times per unit } \\
\text { time }\left(\mathrm{h}^{-1}\right)\end{array}$ & Failure rate & $\begin{array}{c}\text { Maintenance } \\
\text { rate }\left(\mathrm{h}^{-1}\right)\end{array}$ & $\begin{array}{l}\text { Average } \\
\text { working } \\
\text { time }(\mathrm{h})\end{array}$ & $\begin{array}{c}\text { Average } \\
\text { maintenance } \\
\text { time }(\mathrm{h})\end{array}$ & $\begin{array}{c}\text { Average life } \\
\text { cycle (h) }\end{array}$ \\
\hline lue & 00 & 0.00077 & 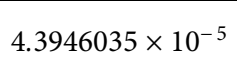 & $4.3980281 \times$ & & 463 & 43 & 84 \\
\hline
\end{tabular}

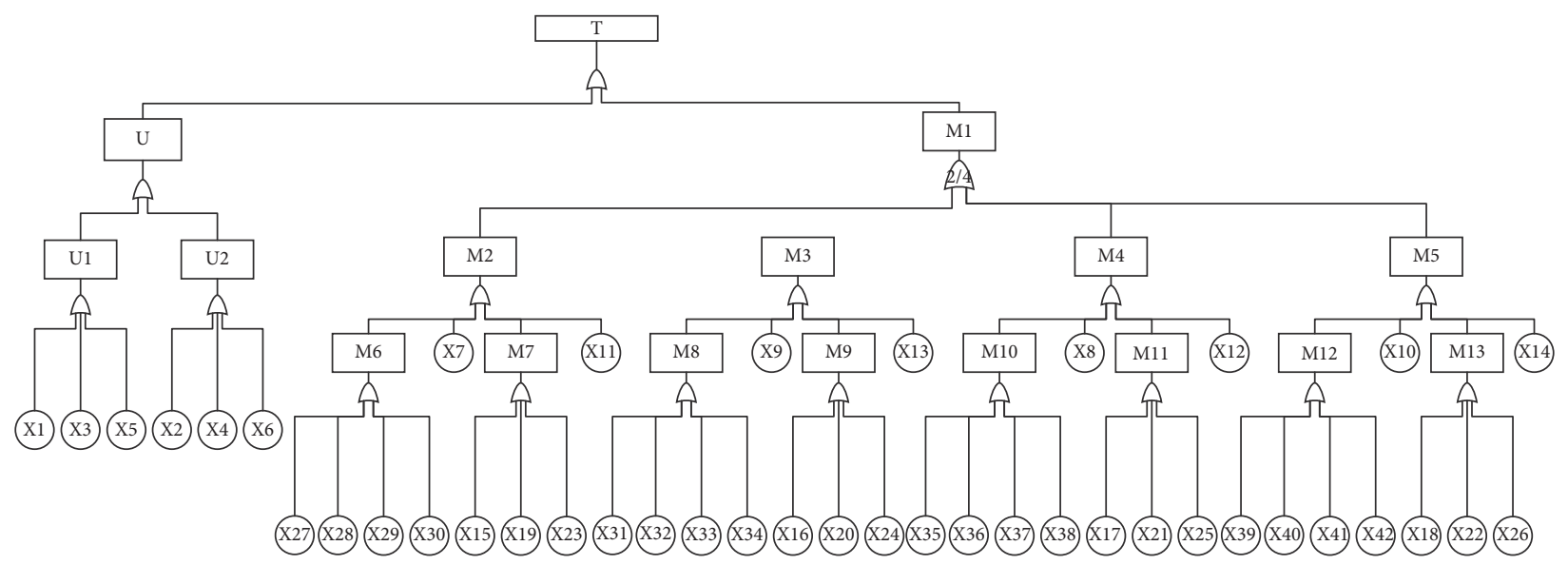

Figure 7: The fault tree model of the MTS.

The MTS has 42 function operators to represent the system components. Through the qualitative analysis of the state probability, it is found that there are 6 first-order minimum cut sets and 486 second-order minimum cut sets. The combination of operator failures in the minimum cut set represents the combination of system component failures. The product of these components failure probabilities represents the probability of the minimum cut set. Through calculation and analysis, there are two first-order minimum cut sets with the greatest probability according to Table 1. The probability is 0.0003 , and they are composed of pantograph. It shows that the pantograph is the weak link of the system and should be taken as the focus on the maintenance of the MTS.

4.4. Reliability Analysis of the MTS Based on FTA. To verify the effectiveness of the GO method, FTA is introduced to determine the reliability of the MTS. Take the MTS failure as the top event, the fault tree model is established as shown in Figure 7 . The event represented by the corresponding code in failure tree is shown in Table 14. There are 42 bottom events in the system, and the failure probability of bottom events is shown in Table 1.

Through the simulation analysis of the fault tree model, it can be concluded that the system has 6 first-order minimum cut sets and 486 second-order minimum cut sets. The first-order minimum cut set probability of pantograph failure is the highest, which is consistent with the qualitative analysis result of the GO method. And it can be concluded that the failure probability of the metro traction system is 0.000779087 . The calculation result of the GO method is 0.000779 . The quantitative calculation results of the two methods are close. It shows that the reliability analysis of metro traction system by the GO method is reasonable, but the results are slightly different. The main reason is that the correlation in the repairable system is not considered by fault tree. The reliability of the repairable system is reduced to a certain extent. Comparing the GO model and fault tree model of the MTS, it can be seen that the GO model can intuitively reflect the working process of MTS. The GO model has a clear logic and compact structure. The logic confusion caused by the multilevel of fault tree is not easy to happen in the GO model. 
TABLE 14: The event represented by the corresponding code in failure tree.

\begin{tabular}{|c|c|c|}
\hline Number & Code & Event \\
\hline 1 & $\mathrm{~T}$ & The MTS failure \\
\hline 2 & $\mathrm{U}$ & High voltage apparatus failure \\
\hline 3 & U1 & High voltage apparatus 1 failure \\
\hline 4 & $\mathrm{U} 2$ & High voltage apparatus 2 failure \\
\hline 5 & M1 & Each branch failure \\
\hline 6 & M2 & Branch 1 failure \\
\hline 7 & M3 & Branch 2 failure \\
\hline 8 & M4 & Branch 3 failure \\
\hline 9 & M5 & Branch 4 failure \\
\hline 10 & M6 & Motor system failure \\
\hline 11 & M7 & Converter system failure \\
\hline 12 & M8 & Motor system failure \\
\hline 13 & M9 & Converter system failure \\
\hline 14 & M10 & Motor system failure \\
\hline 15 & M11 & Converter system failure \\
\hline 16 & M12 & Motor system failure \\
\hline 17 & M13 & Converter system failure \\
\hline 18 & $\mathrm{X} 1$ & Pantograph failure \\
\hline 19 & $\mathrm{X} 2$ & Pantograph failure \\
\hline 20 & $\mathrm{X} 3$ & Surge arrester failure \\
\hline 21 & $\mathrm{X} 4$ & Surge arrester failure \\
\hline 22 & $\mathrm{X} 5$ & Isolating switch failure \\
\hline 23 & X6 & Isolating switch failure \\
\hline 24 & $\mathrm{X} 7$ & High-speed circuit breaker failure \\
\hline 25 & $\mathrm{X} 8$ & High-speed circuit breaker failure \\
\hline 26 & X9 & High-speed circuit breaker failure \\
\hline 27 & $\mathrm{X} 10$ & High-speed circuit breaker failure \\
\hline 28 & $\mathrm{X} 11$ & Wave filter failure \\
\hline 29 & $\mathrm{X} 12$ & Wave filter failure \\
\hline 30 & $\mathrm{X} 13$ & Wave filter failure \\
\hline 31 & $\mathrm{X} 14$ & Wave filter failure \\
\hline 32 & $\mathrm{X} 15$ & Charging circuit failure \\
\hline 33 & $\mathrm{X} 16$ & Charging circuit failure \\
\hline 34 & $\mathrm{X} 17$ & Charging circuit failure \\
\hline 35 & $\mathrm{X} 18$ & Charging circuit failure \\
\hline 36 & $\mathrm{X} 19$ & Controller of converter failure \\
\hline 37 & $\mathrm{X} 20$ & Controller of converter failure \\
\hline 38 & $\mathrm{X} 21$ & Controller of converter failure \\
\hline 39 & $\mathrm{X} 22$ & Controller of converter failure \\
\hline 40 & $\mathrm{X} 23$ & Converter module failure \\
\hline 41 & $\mathrm{X} 24$ & Converter module failure \\
\hline 42 & $\mathrm{X} 25$ & Converter module failure \\
\hline 43 & $\mathrm{X} 26$ & Converter module failure \\
\hline 44 & $\mathrm{X} 27$ & Traction motor failure \\
\hline 45 & $\mathrm{X} 28$ & Traction motor failure \\
\hline 46 & $\mathrm{X} 29$ & Traction motor failure \\
\hline 47 & $\mathrm{X} 30$ & Traction motor failure \\
\hline 48 & $\mathrm{X} 31$ & Traction motor failure \\
\hline 49 & $\mathrm{X} 32$ & Traction motor failure \\
\hline 50 & $\mathrm{X} 33$ & Traction motor failure \\
\hline 51 & $\mathrm{X} 34$ & Traction motor failure \\
\hline 52 & $\mathrm{X} 35$ & Traction motor failure \\
\hline 53 & X36 & Traction motor failure \\
\hline 54 & $\mathrm{X} 37$ & Traction motor failure \\
\hline 55 & $\mathrm{X} 38$ & Traction motor failure \\
\hline 56 & $\mathrm{X} 39$ & Traction motor failure \\
\hline 57 & $\mathrm{X} 40$ & Traction motor failure \\
\hline 58 & $\mathrm{X} 41$ & Traction motor failure \\
\hline 59 & $\mathrm{X} 42$ & Traction motor failure \\
\hline
\end{tabular}

\section{Conclusion}

This paper proposed a reliability assessment based on the GO method of the MTS. The reparability and shutdown correlation of many electrical components in the MTS are considered. The accurate quantitative calculation and qualitative analysis of the system are completed by this method without operation service failure of the metro vehicle. The accurate quantitative calculation results are compared with the quantitative calculation result of all components regarded as completely independent. It is found that the complex correlation in the repairable system has an important effect on the reliability of the system. To verify the correctness and feasibility of the GO method in reliability analysis of the MTS, the analysis results of the GO method are compared with the simulation results of FTA. The qualitative results based on FTA and the qualitative results based on the GO method are consistent. The quantitative results based on FTA is approaching the quantitative results based on the GO method. The comparison results show that the GO method is correct and feasible for the reliability analysis of the MTS considering shutdown correlation. The principle of the GO method is simple and the logic is clear. It can not only objectively reflect the working process of the MTS, but also fully characterize the complex correlation with shut down fault in the MTS. It has theoretical guiding significance for the reasonable formulation of reliability management measures for the MTS.

\section{Data Availability}

The data used to support the findings of this study are included within the article.

\section{Conflicts of Interest}

The authors declare that there are no conflicts of interest regarding the publication of this article.

\section{Acknowledgments}

This work was supported in part by the National Natural Science Foundation of China under Contract 51875073, in part by the Scientific Research Project of Education Department of Liaoning Province under Contract JDL2019005, in part by the Dalian Science and Technology Innovation Fund Plan under Contract 2019J11CY017, and in part by the Innovation Team Support Plan of Liaoning Higher Education under Contract LT2016010.

\section{References}

[1] D. Meng, Y. Li, S.-P. Zhu, Z. Hu, T. Xie, and Z. Fan, "Collaborative maritime design using sequential optimisation and reliability assessment," Proceedings of the Institution of Civil Engineers-Maritime Engineering, vol. 173, no. 1, pp. 3-12, 2020.

[2] D. B. Meng, Z. G. Hu, P. Wu, S. P. Zhu, J. A. F. O. Correia, and A. M. P. De Jesus, "Reliability-based optimization for offshore 
structures using saddlepoint approximation," Proceedings of the Institution of Civil Engineers-Maritime Engineering, vol. 173, no. 2, pp. 33-42, 2020.

[3] D. B. Meng, T. W. Xie, P. Wu, S. P. Zhu, Z. G. Hu, and Y. Li, "Uncertainty-based design and optimization using first order saddlepoint approximation method for multidisciplinary engineering systems," ASCE-ASME Journal of Risk and Uncertainty in Engineering Systems, Part A: Civil Engineering, vol. 6, no. 3, Article ID 04020028, 2020.

[4] L. H. Meng, Z. G. Liu, L. Y. Diao, C. M. Xun, and L. Wang, "Evaluation of reliability of urban rail train traction inverter system," Journal of The China Railway Society, vol. 36, no. 9, pp. 34-38, 2014.

[5] J. Ding, P. Zhang, and J. H. Li, "Fatigue life prediction of IGBT module for metro vehicle traction converter based on traction calculation," in Proceedings of the 2015 IEEE 11th International Conference on Power Electronics and Drive Systems, Sydney, Australia, June 2015.

[6] X. Perpiñà, J. F. Serviere, X. Jordà et al., "IGBT module failure analysis in railway applications," Microelectronics Reliability, vol. 48, no. 8-9, pp. 1427-1431, 2008.

[7] S. S. Moosavi, A. Djerdir, Y. Ait-Amirat, and D. A. Kkuburi, "Artificial neural networks based fault detection in 3-Phase PMSM traction motor," in Proceedings of the 2012 20th International Conference on Electrical Machines (ICEM), Marseille, France, September 2012.

[8] D. L. Song, W. H. Zhang, G. M. Mei, and J. B. Wang, "Static reliability analysis on pantograph of V500 type," in Proceedings of the 2010 WASE International Conference on Information Engineering, Beidaihe, China, August 2010.

[9] J. Q. Liu, S. Li, Y. Jiang, and M. Krishnamurthy, "Reliability evaluating for traction drive system of high-speed electrical multiple units," in Proceedings of the 2013 IEEE Transportation Electrification Conference and Expo (ITEC), Detroit, MI, USA, June 2013.

[10] L. H. Meng, Z. G. Liu, L. Y. Diao, C. M. Xun, and L. Wang, "Reliability evaluation of high-speed train traction transmission system based on Markov model," Journal of The China Railway Society, vol. 38, no. 8, pp. 23-27, 2016.

[11] Z. P. Shen, Y. Wang, and X. R. Huang, "A quantification algorithm for a repairable system in the GO methodology," Reliability Engineering \& System Safety, vol. 80, pp. 293-298, 2003.

[12] X. J. Yi, J. Shi, H. N. Mu, H. P. Dong, and S. W. Guo, "Reliability analysis of hydraulic steering system with DICLFL considering shutdown correlation based on GO methodology," in Proceedings of the 2015 First International Conference on Reliability Systems Engineering, Beijing, China, October 2015.

[13] X. J. Yi, H. P. Dong, Q. F. Wang, and Z. Zhang, “A new system reliability analysis method: the current development of GO methodology in China," WIT Transactions on Engineering Sciences, vol. 109, pp. 222-229, 2015.

[14] M. W. Chen, "The reliability assessment of traction substation of high speed railway by the GO methodology," Power System Protection and Control, vol. 39, no. 18, pp. 56-61, 2011.

[15] Y. Chen, Y. Ren, L. Liu, and D. Yang, "A new algorithm of GO methodology based on minimal path set," AASRI Procedia, vol. 3, pp. 368-374, 2012.

[16] K. Bao, X. J. Yi, Y. F. Chen, and Z. Zhang, "A mean life evaluation method for complex multi-function systems based on GO method: case study of vehicle transmission system," in Proceedings of the 2017 IEEE International Conference on
Industrial Engineering and Engineering Management (IEEM), Singapore, December 2017.

[17] Z. Q. Gao, H. F. Sun, and Q. Wu, "Reliability analysis of the manufacturing system based on GO methodology," $\mathrm{Me}$ chanical Science and Technology, vol. 26, no. 3, pp. 320-323, 2007.

[18] Y. Wang, Z. J. Gu, B. Lian, J. Yang, and Y. J. Zhao, "Reliability analysis of the gasification process of nuclear fuel anufacturing facilities based on the GO methodology," Nuclear Science and Techniques, vol. 30, p. 154, 2019.

[19] X.-j. Yi, B. S. Dhillon, J. Shi, H.-n. Mu, and H.-p. Dong, "Reliability analysis method on repairable system with standby structure based on goal oriented methodology," Quality and Reliability Engineering International, vol. 32, no. 7, pp. 2505-2517, 2015.

[20] G. L. Chen, H. N. Mu, X. J. Yi, Y. Y. Yang, and P. Hou, "Reliability analysis method for pyrotechnic system considering typical characteristics based on GO method," in Proceedings of the 2018 International Conference on Sensing, Diagnostics, Prognostics, and Control Method, Xi'an, China, August 2018.

[21] J. W. Yang, Y. Q. Yang, J. H. Wang, R. Sun, and X. H. Qiu, "Reliability evaluation of TGN15 type IGBT traction inverter for Beijing metro," in Proceedings of the 2019 International Conference on Quality, Reliability, Risk, Maintenance, and Safety Engineering, Zhangjiajie, China, August 2019.

[22] L. M. Jia and S. Lin, "Current status and prospect for the methods of system reliability," Systems Engineering and Electronic, vol. 37, no. 12, pp. 2887-2893, 2015.

[23] G. Qian and W.-S. Lei, "A statistical model of fatigue failure incorporating effects of specimen size and load amplitude on fatigue life," Philosophical Magazine, vol. 99, no. 17, pp. 2089-2125, 2019.

[24] G. Qian, W.-S. Lei, M. Niffenegger, and V. F. GonzálezAlbuixech, "On the temperature independence of statistical model parameters for cleavage fracture in ferritic steels," Philosophical Magazine, vol. 98, no. 11, pp. 959-1004, 2018.

[25] Z. Shen, X. Dai, and X. Huang, "A supplemental algorithm for the repairable system in the GO methodology," Reliability Engineering \& System Safety, vol. 91, no. 8, pp. 940-944, 2006.

[26] Z. P. Shen, J. Gao, and X. R. Huang, "An exact algorithm dealing with shared signails in the GO methodology," Reliability Engineering \& System Safety, vol. 73, pp. 177-181, 2001.

[27] S. Lin, X. Fang, F. Lin, Z. Yang, and X. Wang, "Reliability of rail transit traction drive system-a review," Microelectronics Reliability, vol. 88-90, pp. 1281-1285, 2018.

[28] A. P. Basu and K. Sun, "Multivariate exponential distributions with constant failure rates," Journal of Multivariate Analysis, vol. 61, no. 2, pp. 159-169, 1997.

[29] G. A. Qian, W. S. Lei, L. Peng, Z. Yu, and M. Niffengger, "Statistical assessment of notch toughness against cleavage fracture of ferritic steels," Fatigue \& Fracture of Engineering Materials \& Structures, vol. 41, no. 3, pp. 1120-1131, 2018.

[30] R. Liu, P. Chen, X. Zhang, and S. Zhu, "Non-shock ignition probability of octahydro-1,3,5,7-tetranitro-tetrazocine-based polymer bonded explosives based on microcrack stochastic distribution," Propellants, Explosives, Pyrotechnics, vol. 45, no. 4, pp. 568-580, 2020. 